\title{
Annotations
}

\section{Evaluation and management of precocious puberty}

Puberty is the developmental process that gives rise to secondary sexual characteristics and the capacity to reproduce. Puberty beginning before the age of 8 years in girls or 9 years in boys is considered precocious. The incidence of precocious puberty is estimated to be between 1:5000 and 1:10 000. ${ }^{1}$ Puberty can occur prematurely as one tail of the normal distribution of pubertal timing (a variant of normal) or because of pathologically increased sex steroid concentrations. In general, precocious puberty can be classified as luteinising hormone releasing hormone (LHRH) independent or LHRH dependent.

\section{Normal puberty}

In girls, puberty typically begins with breast development (thelarche) between 8 and 13 years of age, although approximately $15 \%$ of girls develop pubic hair before thelarche. In boys, puberty begins with testicular enlargement, between 9 and 14 years of age. The normal progression of secondary sexual development has been classified into five stages, beginning with stage 1 (prepubertal) and concluding with stage 5 (adult). ${ }^{2}$ Puberty is also accompanied by a growth spurt that approximately doubles the child's prepubertal growth rate. Adrenarche is a maturational process involving the zona reticularis of the adrenal gland resulting in an increase in adrenal androgen secretion which stimulates the development of pubic and axillary hair. This event is independent of gonadarche (activation of the gonads).

The mechanism underlying the activation of hypothalamic LHRH secretion at puberty is currently unknown. Luteinising hormone (LH) and follicle stimulating hormone (FSH) are secreted in a pulsatile manner, even in the prepubertal child. Gonadotropin levels rise gradually throughout puberty, with increased peak amplitude at night from stages 1 to 4 ; however, by stage 5, day-night differences disappear. ${ }^{3}$ The gonadotropin response to intravenous synthetic LHRH changes at puberty from an FSH predominant to an LH predominant response.

\section{Differential diagnosis}

The most common forms of sexual precocity are premature thelarche (isolated premature breast development), and premature adrenarche (isolated sexual hair development). Premature thelarche most commonly occurs before 2 years of age, may begin at birth, and may be unilateral or bilateral. Breast development rarely progresses beyond stage 3 and may resolve spontaneously. Premature adrenarche is the early appearance of pubic hair (below 8 years in a girl or 9 in a boy) due to the early occurrence of the adrenarchal rise of adrenal androgen secretion. Neither condition progresses to full blown puberty and neither is associated with major increases in the rate of growth or bone maturation.

If a child has more than isolated breast or pubic hair development, or also has an increase in growth rate or bone maturation (by more than two standard deviations), then the many causes of precocious puberty must be considered. Isosexual (appropriate for sex) development may reflect either an LHRH dependent or LHRH independent mechanism; contrasexual (appropriate for the opposite sex) development, such as a feminised boy or a virilised girl, implies an LHRH independent mechanism.

Thelarche variant is a condition in which the clinical findings are intermediate between premature thelarche and precocious puberty, and may be due to a disorder of ovarian follicular maturation ${ }^{4}$ since mean ovarian volume slightly exceeds the normal prepubertal size, yet gonadotropin secretion is indistinguishable from that in premature thelarche. Cyclic breast growth may be seen, often with associated growth acceleration and bone age advancement. Patients do not progress to precocious puberty, nor does the breast development spontaneously resolve, as it may in premature thelarche.

\section{LHRH dependent precocious puberty}

Precocious activation of the hypothalamic-pituitarygonadal axis is referred to as LHRH dependent or central precocious puberty. Idiopathic precocious puberty accounts for the majority of cases in girls, but less than $10 \%$ of cases in boys, ${ }^{5}$ and is a diagnosis of exclusion. The underlying mechanism appears to be the same as that of normal puberty, except for the earlier age of onset.

Central nervous system (CNS) tumours can also cause LHRH dependent precocious puberty. Hypothalamic hamartomas are the most common CNS lesion associated with precocious puberty. They are congenital, nonprogressing, LHRH producing masses. ${ }^{6}$ Neurofibromatosis may lead to precocious puberty with or without an optic glioma. ${ }^{7}$ Other CNS lesions may cause precocious puberty (table 1). Moreover, precocious puberty may occur long after a CNS injury.

\section{LHRH independent precocious puberty}

Precocious sex steroid secretion that is independent of pituitary gonadotropin is referred to as LHRH independent, peripheral, or pseudoprecocious puberty. $\mathrm{LH}$ and FSH concentrations are low and response to exogenous LHRH is suppressed. Exposure to increased sex hormones, however, can lead to CNS maturation and subsequent secondary LHRH dependent precocious puberty. As a result, the presence of central precocious puberty does not exclude the possibility of an underlying LHRH independent cause.

Congenital adrenal hyperplasia is a common cause of LHRH independent precocious puberty. The classic forms of 21-hydroxylase and 11-hydroxylase deficiency cause virilisation, growth acceleration, and accelerated bone maturation. Unless secondary central activation has occurred, boys will not have testicular enlargement and girls will not have breast development. The non-classical, or late onset form of congenital adrenal hyperplasia may present in childhood or adolescence with early pubic hair and acne, or in early adulthood with menstrual irregularity, hirsutism, or infertility. Approximately $5-10 \%$ of children with premature adrenarche are estimated to have late onset congenital adrenal hyperplasia. ${ }^{8}$ 
Table 1 Lesions causing precocious puberty

\begin{tabular}{|c|c|}
\hline Disorder & Phenotype \\
\hline Premature thelarche or thelarche variant & $\begin{array}{r}\text { Isolated breast } \\
\text { development }\end{array}$ \\
\hline Premature adrenarche & $\begin{array}{l}\text { Isolated pubic hair } \\
\text { development }\end{array}$ \\
\hline LHRH dependent precocious puberty & $\begin{array}{l}\text { Isosexual } \\
\text { development }\end{array}$ \\
\hline \multicolumn{2}{|l|}{ Idiopathic } \\
\hline \multicolumn{2}{|l|}{ CNS lesion } \\
\hline \multicolumn{2}{|l|}{ Hypothalamic hamartoma } \\
\hline \multicolumn{2}{|l|}{ Other tumours } \\
\hline \multirow{2}{*}{\multicolumn{2}{|c|}{ Astrocytoma }} \\
\hline & \\
\hline \multirow{2}{*}{\multicolumn{2}{|c|}{$\begin{array}{l}\text { Glioma (often associated with neurofibromatosis) } \\
\text { Other CNS lesions }\end{array}$}} \\
\hline \multirow{2}{*}{\multicolumn{2}{|c|}{$\begin{array}{l}\text { Other CNS lesions } \\
\text { Head trauma }\end{array}$}} \\
\hline & \\
\hline \multicolumn{2}{|l|}{ Infections (meningitis, encephalitis, abscess) } \\
\hline \multicolumn{2}{|l|}{ Empty sella syndrome } \\
\hline \multicolumn{2}{|l|}{ Ventricular cysts } \\
\hline \multirow{2}{*}{\multicolumn{2}{|c|}{$\begin{array}{l}\text { Granulomas } \\
\text { econdary to LHRH ind }\end{array}$}} \\
\hline & \\
\hline LHRH independent precocious puberty & $\begin{array}{l}\text { Isosexual or } \\
\text { contrasexual } \\
\text { development }\end{array}$ \\
\hline \multicolumn{2}{|l|}{ Adrenal } \\
\hline 21-hydroxylase deficiency & $\begin{array}{l}\text { Contrasexual } \\
\text { (girls) }\end{array}$ \\
\hline 11-hydroxylase deficiency & $\begin{array}{l}\text { Contrasexual } \\
\text { (girls) }\end{array}$ \\
\hline Tumour & $\begin{array}{l}\text { Isosexual or } \\
\text { contrasexual }\end{array}$ \\
\hline \multicolumn{2}{|l|}{ Gonadal } \\
\hline McCune-Albright syndrome & Isosexual \\
\hline Familial male & Isosexual \\
\hline Tumour & $\begin{array}{l}\text { Isosexual or } \\
\text { contrasexual }\end{array}$ \\
\hline $\begin{array}{l}\text { Ectopic hCG secreting tumour } \\
\text { Gonadal (such as, choriocarcinoma) }\end{array}$ & Isosexual (boys) \\
\hline \multicolumn{2}{|l|}{$\begin{array}{l}\text { Extragonadal (such as, hepatoblastoma, germ cell } \\
\text { tumour of the CNS or mediastinum) }\end{array}$} \\
\hline Exposure to exogenous sex steroids & $\begin{array}{l}\text { Isosexual or } \\
\text { contrasexual }\end{array}$ \\
\hline Massive extraglandular aromatisation & $\begin{array}{l}\text { Contrasexual } \\
\text { (boys) }\end{array}$ \\
\hline Severe hypothyroidism & Isosexual \\
\hline
\end{tabular}

CNS = central nervous system; hCG = human chorionic gonadotropin; LHRH $=$ luteinising hormone releasing hormone.

Tumours of the adrenal gland, ovary, or testes may cause virilisation or feminisation depending on whether androgens or oestrogens are secreted. These rare neoplasms require surgery or chemotherapy or both. Human chorionic gonadotropin (hCG) secreting tumours can cause precocious puberty in boys by stimulating Leydig cells to secrete testosterone. Unlike boys, girls with hCG secreting tumours generally do not develop precocious puberty. Both LH and FSH stimulation are necessary for ovarian activation.

Familial male limited precocious puberty, known also as testotoxicosis, is an autosomal dominant disorder that occurs only in boys, with signs of puberty beginning at approximately 2 years of age. It is caused by constitutively activating mutations of the LH receptor. ${ }^{9}$ Testosterone is markedly raised, and gonadotropin levels are low.

The McCune-Albright syndrome causes precocious puberty, primarily in girls. The classic disorder comprises the triad of polyostotic fibrous dysplasia, cafe-au-lait pigmentation, and LHRH independent precocious puberty. The disorder results from an activating somatic mutation in Gs, the protein that transduces the signal of many 7-transmembrane domain receptors, including the gonadotropin receptor. ${ }^{10}$ Another rare disorder, massive extraglandular aromatisation, causes feminisation at the time of adrenarche. ${ }^{11}$

Severe hypothyroidism may rarely result in precocious puberty and, unlike other causes, is associated with skeletal and growth delay. The pathophysiology is uncertain, but it may be due to the intrinsic FSH activity of very high TSH levels. ${ }^{12}$ The puberty is reversible with thyroid hormone administration.

\section{Diagnostic evaluation}

Evaluation of the child with premature puberty depends on the clinical features. At a minimum, an $x$ ray of the left hand should be done to determine bone age. Further investigation is warranted if the bone age is more than two standard deviations above chronologic age.

The history should include the rate of pubertal progression, and the presence or absence of acne, body odour, oiliness of the skin, erections and nocturnal emissions in boys, and vaginal discharge or bleeding in girls. Parents may also describe an increase in growth rate. A family history of unexplained early death in a male sibling may suggest congenital adrenal hyperplasia. Precocious puberty in male relatives suggests familial male limited precocious puberty.

An LHRH test determines whether there is activation of the hypothalamic-pituitary axis, and helps to differentiate between LHRH dependent and LHRH independent disorders. An intravenous bolus of LHRH $(100 \mu \mathrm{g})$ is given and $\mathrm{LH}$ and FSH are measured at 30 and 60 minutes. A pubertal response is defined by an LH predominant response. Cut offs vary depending on the assay, and sex differences have been found. ${ }^{3}$ Recent studies suggest that a baseline LH level may be a useful screening method when using a highly sensitive immunochemiluminometric assay. ${ }^{13}$ If a child is diagnosed with LHRH dependent precocious puberty, a computed tomographic scan or magnetic resonance imaging of the head is indicated. In addition, patients with idiopathic precocious puberty should be evaluated for underlying causes of LHRH independent puberty, since these causes may induce secondary central precocious puberty.

If the clinical features are consistent with premature thelarche (isolated breast development without accelerated growth or bone maturation), the patient may simply be followed clinically at intervals of three to six months. Further evaluation is necessary only if other signs of puberty develop, or if the bone age becomes advanced. A pelvic ultrasound may also be useful in the evaluation of premature thelarche. Multicystic morphology ( $>6$ cysts of $4 \mathrm{~mm}$ in diameter or greater) is typically seen in girls with precocious puberty, while girls with premature thelarche typically have less than three cysts, and girls with thelarche variant have intermediate findings. ${ }^{4}$

In the case of isolated sexual hair development and suspected premature adrenarche, the diagnosis of nonclassical adrenal hyperplasia should be excluded by an ACTH test. Cosyntropin $(0.25 \mathrm{mg})$ is given and 17-hydroxyprogesterone is measured at 60 minutes. A level of 17-hydroxyprogesterone greater than $48 \mathrm{nmol} / 1$ (1500 $\mathrm{ng} / \mathrm{dl}$ ) indicates non-classical 21-hydroxylase deficiency. ${ }^{14}$

Rapid virilisation suggests the possibility of an endocrine secreting neoplasm. In adrenal tumours, both testosterone and dihydroepiandrosterone are usually markedly elevated. A raised serum hCG suggests an hCG secreting tumour. $\alpha$-Fetoprotein and carcinoembryonic antigen (CEA) are potentially useful markers of nongerminomatous germ cell tumours. If the child has short stature, delayed bone age, or signs of hypothyroidism, thyroid function tests should be performed. If McCuneAlbright syndrome is suspected because of cafe-au-lait spots, fractures, or early menstrual bleeding, a skeletal survey or bone scan is indicated.

\section{Treatment}

Premature thelarche and premature adrenarche do not require treatment. Initially, the child should be seen every 
three to six months to confirm the diagnosis through the lack of pubertal progression. The decision to treat precocious puberty is based on several factors including the child's age, the emotional impact of experiencing early puberty, and the predicted height.

The treatment of LHRH dependent precocious puberty is an LHRH agonist, which inhibits normal gonadotropin secretion. The long acting intramuscular depot preparation of leuprolide is probably the most commonly used ( $0.3 \mathrm{mg} / \mathrm{kg}$ every three to four weeks). Leuprolide is also available as a short acting subcutaneous formulation, effective at daily doses of $30-100 \mu \mathrm{g} / \mathrm{kg}$. Histrelin, available in a subcutaneous formulation, is effective at the daily dose of $10 \mu \mathrm{g} / \mathrm{kg}$. Other LHRH analogue preparations include deslorelin $(4 \mu \mathrm{g} / \mathrm{kg} / \mathrm{d})$, a daily subcutaneous formulation, nafarelin and buserelin, intranasal sprays, and triptorelin, a long acting depot formulation.

Similar results can be obtained with each of the available LHRH analogues provided that adequate gonadotropin suppression is achieved; however, gonadotropin suppression has often been less complete with the intranasal formulations. Suppression is most effectively monitored by a peak LH following an LHRH test, usually performed three months after start of treatment. Further biochemical evaluation may not be necessary if gonadotropin suppression is achieved, growth velocity and bone maturation return to prepubertal rates, and pubertal progression is arrested. Treatment of precocious puberty with LHRH agonist has been shown to improve final adult height. ${ }^{15}{ }^{16}$ In general, the earlier the treatment is started, the better the adult height achieved. Discontinuation of treatment should be individualised on the basis of height potential and the patient's and parents' wishes.

Before the introduction of LHRH agonist therapy, synthetic progestational agents were routinely used in the treatment of precocious puberty. Cyproterone acetate, a progestational compound, has been used extensively in the treatment of precocious puberty but long term gonadotropin suppression is less effective than with LHRH agonist treatment. Cyproterone acetate has also been used in the early stages of LHRH agonist treatment to prevent the initial stimulatory effect of LHRH agonist which may occur before its inhibitory effect. ${ }^{17}$ This compound is not currently used in the United States, but is used in Europe, Japan, and elsewhere.

Two treatments are available for familial male precocious puberty: (1) the combination of testolactone and spironolactone, ${ }^{18}$ and (2) ketoconazole. ${ }^{19}$ Ketoconazole inhibits the biosynthesis of testosterone. Spironolactone blocks the action of androgen, and testolactone blocks the conversion of androgen to estrogen. The side effects of ketoconazole include gastrointestinal distress and, rarely, hepatotoxicity. The main side effect of testolactone and spironolactone treatment is transient gastrointestinal distress.

Testolactone is effective in treating girls with McCuneAlbright syndrome at a dose of $40 \mathrm{mg} / \mathrm{kg} /$ day divided in three doses. Unfortunately, escape from the effects of treatment may occur after one to three years. ${ }^{20}$ After years of exposure to oestrogen, many of these girls enter central precocious puberty and require treatment with an LHRH analogue.

Children with non-classical congenital adrenal hyperplasia usually do not require treatment and, untreated, usually attain normal adult height. If treatment is indicated, an adequate response can normally be achieved with a hydrocortisone dose not exceeding $10 \mathrm{mg} / \mathrm{m}^{2} /$ day. The classic form of congenital adrenal hyperplasia requires glucocorticoid treatment, usually hydrocortisone $12-15 \mathrm{mg} / \mathrm{m}^{2} /$ day. Classic 21-hydroxylase deficiency, whether salt wasting or simple virilising, also requires mineralocorticoid replacement, usually fludrocortisone $0.1-0.2 \mathrm{mg} /$ day.

Surgery is rarely indicated in children with central precocious puberty. Although precocious puberty may be cured by the removal of pedunculated hamartomas, ${ }^{21}$ we prefer medical treatment for this disorder. hCG secreting dysgerminomas can be cured by radiotherapy. If the presence of $\alpha$-fetoprotein or CEA suggests a nongerminomatous germ cell tumour, treatment should include chemotherapy.

\section{Conclusion}

Premature sexual development comprises a spectrum of disorders including premature thelarche, premature adrenarche, and LHRH dependent and LHRH independent forms of precocious puberty. Premature thelarche and premature adrenarche represent benign conditions that require no treatment. By contrast, LHRH dependent and independent precocious puberty usually require treatment. The LHRH dependent causes of precocious puberty can be treated effectively with an LHRH agonist, but the decision to treat should be individualised. Treatment of the LHRH independent forms of precocious puberty is determined by the underlying cause.

DEBORAH P MERKE GORDON B CUTLER JR

Developmental Endocrinology Branch,

National Institute of Child Health and Human Development,

National Institutes of Health,

Bethesda, MD 20892, USA

1 Cutler GB. Precocious puberty. In: Hurst JW, ed. Medicine for the practicing physician, 2nd Ed. Woburn, MA: Butterworth, 1988:526-30.

2 Marshall WA, Tanner JM. Variations in pattern of pubertal changes in girls. Arch Dis Child 1969;44:291-303.

3 Oerter KE, Uriarte MM, Rose SR, Barnes KM, Cutler GB. Gonadotropin secretory dynamics during puberty in normal girls and boys. $\mathcal{f}$ Clin Endocrinol Metab 1990;71:1251-8.

4 Stanhope R, Brook CCD. Thelarche variant: a new syndrome of precocious sexual maturation? Acta Endocrinol 1990;123:481-6.

5 Pescovitz OH, Comite F, Hench K, et al. The NIH experience with precocious puberty: diagnostic subgroups and response to short-term luteinizing hormone releasing hormone analogue therapy. $\mathcal{F}$ Pediatr 1986;108:47-54.

6 Judge DM, Kulin HE, Page R, Santen R, Trapukdi S. Hypothalamic hamartoma. A source of luteinizing hormone releasing factor in precocious puberty. N Engl F Med 1977;290:7-10.

7 Laue L, Comite F, Hench K, Loriaux L, Cutler GB, Pescovitz OH. Precocious puberty associated with neurofibromatosis and optic gliomas. Am $\mathcal{F}$ Dis Child 1985;139:1097-100.

8 Balducci R, Boscherini B, Mangiantini A, Morellini M, Toscano V. Isolated precocious pubarche: an approach. $\mathcal{F}$ Clin Endocrinol Metab 1994;79:582-9.

9 Shenker A, Laue L, Kosugi S, Merendino J, Minegishi T, Cutler GB. A constitutively activating mutation of the luteinizing hormone receptor in familial male precocious puberty. Nature 1993;365:652-4.

10 Weinstein LS, Shenker A, Gejman PV, Merino MJ, Friedman E, Spiegel AM. Activating mutations of the stimulating $G$ protein in the McCuneAlbright syndrome. N Engl f Med 1991;325:1688-738.

11 Berkowitz GD, Guermani A, Brown TR, MacDonald PC, Migeon CJ. Familial gynecomastia with increased extraglandular aromatization of plasma carbon 19-steroid. $\mathcal{f}$ Clin Invest 1985;75:1763-9.

12 Anasti JN, Flack MR, Froehlich J, Nelson LM, Nisula BC. A potential novel mechanism for precocious puberty in juvenile hypothyroidism. $\mathcal{F}$ Clin Endocrinol Metab 1995;80:276-9.

13 Neely EK, Wilson DM, Lee PA, Stene M, Hintz RL. Spontaneous serum gonadotropin concentrations in the evaluation of precocious puberty. $f$ Pediatr 1995;127:47-52.

14 Azziz $R$, Dewailly D, Owerback D. Clinical review: nonclassic adrenal hyperplasia: current concepts. 7 Clin Endocrinol Metab 1994;78:810-5.

15 Oerter KE, Manasco P, Barnes KM, Jones J, Hill S, Cutler GB. Adult height in precocious puberty after long-term treatment with deslorelin. $\mathcal{f}$ Clin Endocrinol Metab 1991;73:1235-40.

16 Paul D, Conte FA, Grumback MM, Kaplan SL. Long term effect of gonadotropin-releasing hormone agonist therapy on final and near-final height in 26 children with true precocious puberty treated at a median age of less than 5 years. F Clin Endocrinol Metab 1995;80:546-51.

17 Kauli R, Pertzelan A, Ben-Zeev Z, et al. Treatment of precocious puberty with LHRH analogue in combination with cyproterone acetate-further experience. Clin Endocrinol 1984;20:377-87.

18 Laue L, Kenigsberg D, Pescovitz $\mathrm{OH}$, et al. Treatment of familial male precocious puberty with spironolactone and testolactone. $N$ Engl 7 Med 1989 ; 320:496-502.

19 Holland FJ, Fishman L, Bailey JD, Fazekas ATA. Ketoconazole in the management of precocious puberty not responsive to LHRH-analogue therapy. N Engl f Med 1985;312:1023-8.

20 Feuillan PP, Jones J, Cutler GB. Long term testolactone therapy for precocious puberty in girls with the McCune-Albright syndrome. $\mathcal{F}$ Clin Endocrinol

21 Nishio S, Shigeto H, Fukui M. Hypothalamic hamartoma: the role of surgery. Neurosurg Rev 1993;16:157-60. 